MIT Center for Energy and Environmental Policy Research

\title{
The Future of Nuclear Power After Fukushima
}

\author{
Paul L. Joskow and John E. Parsons
}

February 2012

CEEPR WP 2012-001 

Revision of February 7, 2012

\title{
The Future of Nuclear Power After Fukushima ${ }^{1}$
}

\author{
Paul L. Joskow \\ Alfred P. Sloan Foundation and MIT \\ John E. Parsons \\ MIT
}

\begin{abstract}
This paper analyzes the impact of the Fukushima accident on the future of nuclear power around the world. We begin with a discussion of the 'but for' baseline and the much discussed 'nuclear renaissance.' Our pre-Fukushima benchmark for growth in nuclear generation in the U.S. and other developed countries is much more modest than many bullish forecasts of a big renaissance in new capacity may have suggested. For at least the next decade in developed countries, it is composed primarily of life extensions for many existing reactors, modest uprates of existing reactors as their licenses are extended, and modest levels of new construction. The majority of forecasted new construction is centered in China, Russia and the former states of the FSU, India and South Korea. In analyzing the impact of Fukushima, we break the effect down into two categories: the impact on existing plants, and the impact on the construction of new units. In both cases, we argue that the accident at Fukushima will contribute to a reduction in future trends in the expansion of nuclear energy, but at this time these effects appear to be quite modest at the global level.
\end{abstract}

Keywords: Nuclear power, Fukushima accident, electricity generation.

\section{Introduction}

How will the accident at the Fukushima Daiichi plant in Japan that began on March 11, 2011 affect the future of nuclear power around the world? ${ }^{2}$ There has already been a great deal of speculation on this subject, often based on wishful thinking rather than careful analysis. This is necessarily a counterfactual question and first requires us

\footnotetext{
${ }^{1}$ The views expressed here are our own and to not represent the views of the Alfred P. Sloan Foundation, MIT, or any other organizations or individuals with which we are affiliated.

${ }^{2}$ A good discussion of the timeline of events that ultimately led to the destruction of four of the units at Fukushima and the known releases of radiation can be found in INPO (2011). We provide a capsule summary below.
} 
to develop a "but for Fukushima” baseline for comparison purposes. Constructing such a baseline in turn is quite challenging since even before the Fukushima accident there was considerable uncertainty about the future of nuclear power in different countries and globally related to economic, technological and political factors that are each uncertain and vary from one country to another.

To keep things simple, for our baseline we rely on the 2010 and 2011 long term outlooks produced by the U.S. Energy Information Administration (EIA) that present reference and sensitivity cases to $2035 .^{3}$ These do not take the effects of the Fukushima accident into account and from this perspective do provide the kind of baseline that we seek. There may be better (and worse) forecasts available, but the EIA uses a model that we understand, clearly identifies the assumptions that drive the model and, overall, is much more transparent and objective than others that might be available. We will use this baseline as a starting point and then discuss how the events at Fukushima and a number of other factors may affect the future of nuclear power. Our discussion will be divided between effects on the longevity of existing nuclear plants and the construction of new nuclear plants around the world.

Nuclear power provides a large share of U.S. and global carbon-free dispatchable base load generation today and its continued growth is embedded in many forecasts for future global greenhouse gas (GHG) emissions. Nuclear power accounts for about 20\% of U.S. electricity production and about $13.5 \%$ of global electricity production today.

\footnotetext{
${ }^{3}$ Throughout the paper, data on total electricity generated by nuclear power plants and total electricity generated is for 2008 and forecasted generation is for 2035, and comes from EIA (2011a) and EIA (2011b). Data on the number of reactors in operation and under construction comes from the International Atomic Energy Agency’s Power Reactor Information System (PRIS) on-line database, http://www.iaea.org/programmes/a2/. Data on license renewals and new construction licenses is from the websites of the respective national regulatory agency or industry association.
} 
Indeed, one of the reasons for the much discussed "renaissance of nuclear power" is the recognition that nuclear power represents a potential source of large quantities of carbonfree electricity production for the future from plants that do not create the intermittency problems associated with wind and solar generating technologies (Joskow 2011a, 2011b). Accordingly, significant changes in the expected future paths of electricity generation from both existing and new nuclear generating plants could have significant implications for future investment in electricity generation and electricity networks and for the challenges of meeting aggressive targets for reducing GHG emissions.

It is still quite uncertain whether the accident at Fukushima and the associated releases of radiation will have significant adverse global effects on the continued operation of existing nuclear plants and the level of construction of new nuclear plants. It is fairly clear that there will be some adverse effects on the future of nuclear power compared to the "no Fukushima" counterfactual, so the question is how significant those effects will be. There are two potentially interdependent forces that could lead the Fukushima accident to affect (negatively) the future of nuclear power. First, the lessons learned from the accident may affect safety criteria and procedures for existing and new nuclear generating units. Such changes would likely increase costs for both existing and new nuclear units and perhaps delay deployment of new units. Second, the accident and its consequences may adversely affect public and political support for nuclear power. This could lead some countries to move away from nuclear power for political reasons, make relicensing of existing plants and licensing of new plants more difficult, lead to tighter safety criteria, delay regulatory decisions, and generally increase the costs of existing and new plants. 
It will take a considerable period of time to fully understand the events at Fukushima and what needs to be done to reduce the probability of this kind of catastrophic system failure in the future. We will not know definitively what happened at Fukushima from both technical and managerial response perspectives for some time (e.g. whether and why the primary containments failed in one or more of the units at the Fukushima sites, the reasons for hydrogen buildup and explosions, emergency response procedures and their implementation, and differences in conditions among reactors at different sites and locations around the world). Exactly what the long run responses will be globally and how they will affect the economics of nuclear power generation and the politics associated with acceptance of nuclear power in different countries will remain uncertain for years.

Accordingly, we recognize that there are many relevant uncertainties that must go into our assessment of the most likely effects of the Fukushima accidents on future nuclear generation from both existing and potentially new nuclear power plants in light of what we know today.

\section{What is the "Nuclear Renaissance?"}

There has been a great deal of talk in recent years about a global "nuclear

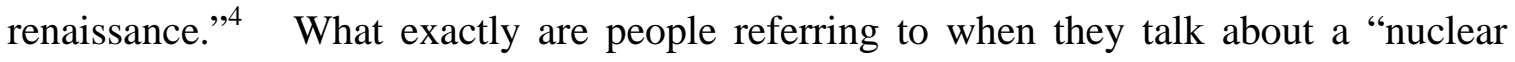
renaissance? In general, we believe that this talk has been driven by a number of factors. First, in the previous two decades, relatively few new nuclear plants were built around the world, and it appeared that except in countries like France, Japan, and South Korea there was little interest in building many new nuclear plants. However, in the decade pre-

\footnotetext{
${ }^{4}$ Nuttal (2005).
} 
Fukushima it appeared that growing interest in and political acceptance for both existing and new nuclear power plants had begun to increase once again. In the three largest producers of electricity from nuclear power (the U.S., France and Japan), plans to extend the licenses and associated operating lives of most of the existing plants were proceeding without much political opposition. Prior to Fukushima, 71 units had been relicensed in the U.S. and 14 more are pending NRC decisions. ${ }^{5}$ Relicensing had begun in Japan prior to the Fukushima accident; indeed Unit \#1 at Fukushima received a 10-year license extension just a month before the accident. France had begun evaluating its nuclear units for 10-year license extensions, with at least one license extension issued in $2011 .^{6}$ Nuclear plants in Canada were being refurbished for continued operation. While the future of the Magnox and AGR units in the UK remain uncertain, life extensions of some of them were being considered. Several countries with strong anti-nuclear lobbies like Germany, Sweden, Italy, Spain and Belgium seemed to be moving away from earlier decisions to close existing nuclear plants early, extending their operating lives, and in the case of Italy and Spain making it possible to build new plants.

On the new construction front, the major nuclear vendors were heavily promoting their latest designs of so-called Generation 3 plants as being safer and more economical than the earlier designs. The U.S. Congress voted to provide large tax credits and loan guarantees to a limited number of new nuclear units and Presidents Bush and Obama supported this policy. A new regulatory process for approving new plants was put in place by the U.S. Nuclear Regulatory Commission (NRC), and applications for about 28

\footnotetext{
${ }^{5}$ http://www.nei.org/resourcesandstats/nuclear_statistics/licenserenewal/

${ }^{6}$ http://www.french-nuclear-safety.fr/index.php/English-version/News-releases/2010/Continued-operationof-reactor-1-at-the-Tricastin-Nuclear-Power-Plant
} 
new units were filed with the U.S. NRC pre-Fukushima. ${ }^{7}$ Construction began on new nuclear units in Finland and France, and commitments were being made to build new nuclear units in the UK. China made a massive commitment to move the share of nuclear production from $1 \%$ of generation (11 GWe) to $6 \%$ of generation (about $100 \mathrm{GWe}$ ) by 2020, with 27 units already under construction at the time of the Fukushima accident. ${ }^{8}$ Through agreements with the U.S. and some other members of the nuclear suppliers' club, India, facing, electricity shortages and rapidly growing electricity demand, was let out of the international nuclear suppliers' dog house and expressed considerable interest in expanding its nuclear fleet with help from vendors in the U.S., France and Russia. Additional construction was anticipated in South Korea, Japan and Taiwan. Perhaps of more interest, a significant number of emerging economies expressed interest in developing nuclear generating facilities as part of their generation portfolio, including Abu Dhabi, Saudi Arabia, Turkey, Egypt, Israel, Jordon, Chile, Venezuela, Vietnam, among others. Indeed, in 2009 Abu Dhabi signed an agreement with a Korean consortium to build four units at a very attractive price. This also marked the entry of a new supplier into the international nuclear plant supply business.

A number of considerations drove this interest in new plants: (a) policies to promote low- and no-carbon electric generation resources to meet targets for global reductions in CO2 emissions by 2020 and 2050 which had favorable effects on political and public policies toward nuclear power; (b) a more favorable regulatory environment in the U.S. for approving applications for new nuclear plants; (c) significant improvements in the performance of nuclear power plants in many countries (though not in Japan), with

\footnotetext{
${ }^{7}$ http://www.nrc.gov/reactors/new-reactors/col.html

8 http://www.world-nuclear-news.org/newsarticle.aspx?id=29080
} 
capacity factors in the U.S. reaching an average of $90 \%$ over the last decade, as safety indicia improved; (d) rising fossil fuel prices, especially natural gas prices during most of the first decade of the $21^{\text {st }}$ century, and concerns, especially in Europe, about dependence on Russia and a few other countries for natural gas supplies; (e) a new generation of nuclear power plants that were designed to be safer and were advertised to have low construction costs and the ability to quickly achieve high capacity factors to make them competitive with alternative base load generating technologies; (f) heavy promotion of these virtues by the major multinational nuclear power vendors and equipment suppliers; (g) announcements by some governments that had previously rejected nuclear power that they would reevaluate their earlier decisions (e.g. Italy, Spain, and Sweden) reflecting the above considerations; (h) interest of many emerging countries to respond to rapidly growing demand for electricity, in part due to assumptions that fossil fuel resources had higher export values than using these resources to generate electricity at home, and in some cases forecasts that domestic supplies of fossil fuels would decline over the coming decades. These considerations led to the expectation that the world was on the verge of a major new program to invest in a large fleet of new nuclear power plants around the world in the coming years, something that had not been seen since the 1970s and a global expansion of the countries operating nuclear power plants. Taken together, these developments led to a lot of optimism that there would indeed be a major "nuclear renaissance.”

Talk is cheap. In our view, this purported nuclear renaissance was more hope or hype than it was a realistic forecast of the future of nuclear power even before Fukushima, especially in developed countries. It is certainly true that there was 
legitimate optimism about life extensions for most of the existing fleet of nuclear plants in the U.S., France, Japan, Canada and other countries, and the prospect for some new nuclear power plants being completed prior to 2020 in the U.S. and some other developed countries was reasonably good prior to Fukushima. However, we do not think that it was likely that a major investment program to build a large fleet of new nuclear power plants, especially in the developed countries, would have taken place over the next couple of decades, even absent Fukushima.

In the U.S. as of year-end 2011, no license for construction of a new reactor has yet been issued (one is close) and real commitments to start construction over the next several years on new units in the U.S. is on the order perhaps 8 new units at 4-5 locations, and there is considerable uncertainty about some of these. The most advanced is Southern Company’s proposed 2 additional units at its Vogtle site in Georgia. The reactor design was recently approved by the NRC, and the combined construction and operating license (COL) is expected in early 2012. Southern has preliminary approval on a loan guarantee from the U.S. government, which can be finalized once the construction license is granted. The next in line are Scana's 2 additional units at its V.C. Summer site in South Carolina. Output is to be shared between Scana’s South Carolina Gas \& Electric unit and Santee Cooper, a state owned corporation that provides power to a collection of local cooperatives. In addition to these, licenses for 1 new unit continue to be pursued by Dominion Resources for its North Anna site in Virginia, and for 2 units by Progress Energy for its Levy County site in Florida. However, decision on construction at these sites is not expected until after licenses are received. Although a number of other units 
have been proposed and some have license applications in the works, at best these are placeholders should circumstances change in the future.

The new construction projects in the U.S. that are moving forward with serious investments being made all had one or both of the following characteristics: (a) they are slated to receive federal loan guarantees and/or (b) they are in states where the plants would be subject to cost of service regulation and were supported by state regulatory commissions rather than competitive wholesale market prices. Both attributes shift risk to taxpayers or to consumers paying regulated prices that pass through actual construction and operating costs. The other license applications in competitive states have been suspended or delayed, with the disagreement about building a third unit at Calvert Cliffs, Maryland between joint owners EDF and Constellation being the best publicized. The project in Texas led by NRG had made some progress in a state that had adopted a competitive wholesale market. Following the Fukushima accident NRG announced it had ceased all capital expenditures and wrote off its investment. TEPCO was one of NRG's partners and after Fukushima its ability to meet its financial commitments was in serious doubt. However, even absent Fukushima, the fate of the Texas plant was very uncertain due in part to economic considerations. ${ }^{9}$

The only reactor actually under construction in the U.S. is TVA's Watts Bar unit 2 on which construction had started in 1972, was subsequently suspended in response to "need" considerations, and construction was only recently restarted based on the original license. ${ }^{10}$

\footnotetext{
${ }^{9}$ http://phx.corporateir.net/External.File?item=UGFyZW50SUQ9OTAwMzB8Q2hpbGRJRD0tMXxUeXBlPTM=\&t=1

${ }^{10} \mathrm{http} / / / \mathrm{www}$. iaea.org/programmes/a2/
} 
Turning to other developed countries, one reactor is under construction in Finland (delayed and over budget), one in France (delayed and over budget), two in Japan (whose future prospects are uncertain) and five in South Korea. There was serious discussion about building new nuclear plants in the UK, Canada, another plant in Finland, and at least one additional plant in France. Prior to Fukushima it appeared that policies forbidding new nuclear plants in Italy, Spain, Belgium, and perhaps other European countries would be reversed, with an expectation that new investment would be forthcoming. However, relatively little money or formal contractual arrangements had been put on the table to build new nuclear plants in Europe other than those already mentioned.

Accordingly, our pre-Fukushima benchmark for growth in nuclear generation in the U.S. and other developed countries is much more modest than many bullish forecasts of a big renaissance in new capacity may have suggested. For at least the next decade in developed countries, it is composed primarily of life extensions for many existing reactors (except in the UK where life extension opportunities are more uncertain), modest uprates of existing reactors as their licenses are extended, and modest levels of new construction in the U.S., Canada, Western Europe and Japan. The EIA's outlook is roughly consistent with this view, but perhaps a bit on the optimistic side: in the U.S. nuclear generation would increase by less than $1 \%$ per year through 2035 , less than $10 \%$ cumulatively, with nuclear's share of total generation falling from $20 \%$ to $17 \%$; in the OECD as a whole, nuclear generation would increase by $1 \%$ per year through $2035,32 \%$ cumulatively, with nuclear's share of total generation constant at $21 \%$. 
The pre-Fukushima forecast in non-OECD countries was dominated by China's stated intention to build about 100 GWe of nuclear capacity by 2020. It also included plans by countries with existing nuclear power sectors such as Russia, other eastern European FSU countries, India, Pakistan and Taiwan to build additional nuclear capacity. In addition, growing interest in construction of new plants was expressed by some developing countries which have no nuclear power plants, especially Turkey and countries in the Persian Gulf. This is consistent with the EIA baseline forecast that we discussed earlier. In non-OECD countries, nuclear generation increases by $6 \%$ per year through 2035, 377\% cumulatively, with the fastest growth in non-OECD Asia at 9.2\% per year to 2035.

This long-term pre-Fukushima baseline is consistent with the pattern of new nuclear plants that are actually under construction. Overall, there are 63 nuclear power plants under construction around the world today (plus 7 completed in 2011), including one in Argentina that has been under construction for 20 years. If there is a major nuclear renaissance it is in China, where 26 new units are under construction, Russia and the former states of the FSU (16), India (6) and South Korea (5).

There are several reasons for the significant differences in the nuclear baselines for the OECD countries (except South Korea) and the non-OECD countries: (a) electricity consumption is forecast to grow much more slowly in the OECD countries than in the less developed countries like China and India; (b) the construction costs of new nuclear plants in developed countries are turning out to be much higher than forecast a few years ago and they may be lower in developing countries—see Du and Parsons (2009) and EIA (2010b); (c) natural gas price forecasts have come down and supply 
increased, with the greatest effects likely in the North America and Europe; (d) the less developed countries are placing considerable weight on learning and internalizing nuclear power technologies as part of a broader development program, and at least in the case of Abu Dhabi, making a thoughtful set of agreements regarding enrichment, reprocessing, and waste storage to mitigate concerns about nuclear proliferation and control costs; (e) energy security concerns, primarily about gas imports; (f) commitments to large investments in wind and solar generating technologies, especially in Europe, which will reduce the net demand for conventional dispatchable technologies and make base load technologies less economical; and (g) the less developed countries have less experience with building, operating and regulating nuclear plants and may be underestimating the true challenges and costs associated with building, operating, and effectively meeting safety standards.

\section{The Effects of Fukushima}

Fukushima Daiichi is the site of six nuclear reactors constructed in the 1970s. It sits on the western or Pacific coast of Japan in a largely rural area about 160 miles north of Tokyo. The Fukushima Prefecture hosts another site further south, Fukushima Daini, with four reactors built in the 1980s. The accident happened at the Daiichi site. On March 11, 2012 at 14:46 JST, a 9.0 earthquake struck about 110 miles off the coast from Fukushima. At the time of the quake, only three reactors at Fukushima Daiichi were in operation, and all three began an automatic emergency shutdown. Although off-station power was lost due to the earthquake, emergency generators started as planned. Less than an hour later, the first of seven Tsunamis reached the site. The maximum height of the 
water was 49 feet, while the design basis for the site was about 33 feet. Water inundated the facilities, shutting off emergency power to units 1, 2, 3 and 4 as well as to waste fuel ponds. Two workers on site were killed after being trapped in a building. Various efforts to restore cooling to the reactor cores and waste fuel pools ensued, but failed. Over the next days, all three reactors suffered explosions from hydrogen, and meltdowns of fuel occurred, penetrating reactor vessels although not the secondary containment structure. Between March 11 and April 5, the site released radiation equivalent to 17 million curies of Iodine-131, which is an order of magnitude less than the release at Chernobyl (378.4 million curies) and much larger than the release at Three Mile Island. As of December 16, 2011, all units at the site were declared to be in cold shutdown. It is currently estimated that cleanup will take 40 years. The estimated costs for the cleanup are yet to be fully tallied. Cleanup after the accident at Three Mile Island cost about $\$ 1$ billion plus the cost of replacement power. However, there was little indirect economic disruption. The accident at Fukushima has already had significant indirect consequences, both in the form of lost generation at multiple nuclear units throughout the country, and also as a result of the evacuation ordered out to 10 miles from the site and the restrictions on transportation and food that have been imposed. ${ }^{11}$

Pre-Fukushima forecasts of global nuclear generation over the next two or three decades were already under pressure for a variety of economic and policy reasons. In our view, the accident at Fukushima will not "kill" the much discussed renaissance of nuclear power, but it adds one more negative pressure on the rate of growth globally. The questions are how much will these effects be and for how long will they last? Here

\footnotetext{
${ }^{11}$ See INPO (2011) for a description of the site, nuclear units operating there, and detailed time line of the accident.
} 
we think that it is useful to distinguish between the future of the existing fleet of nuclear plants and construction of new nuclear plants.

\section{Existing Nuclear Plants}

In the U.S., the events at Fukushima have not yet had any direct effects on the future of existing nuclear plants. License extensions continue and no plants have been closed due to safety concerns. In its mid-cycle assessment conducted after the accident, the NRC inspected all of the 104 operating U.S. nuclear units and declared that the nuclear units operating in the U.S. are safe, while also making a number of recommendations for improving safety and identifying a few specific plants that need to take actions quickly to mitigate fairly minor safety problems. ${ }^{12}$ Of the 104 units inspected, 91 were performing at the highest safety level with no special remedial action or special inspection regime required. Eight more plants needed to take actions to deal with relatively minor safety-related issues. Three other plants were identified as having more significant safety issues requiring remediation. More management attention and NRC inspections were proposed for these plants. Two of the 104 U.S. plants were determined to require a very high level of attention. Owners of U.S. nuclear plants are moving quickly to remedy any safety deficiencies that were identified.

The NRC also created a "90-day" task force to identify near term lessons learned from Fukushima. The Task Force report was issued in July $2011 .^{13}$ It concluded that the basic NRC regulatory framework is sound and that a sequence of events such as occurred at Fukushima is unlikely at U.S. plants, and could be mitigated. The Task Force also concluded that operation and licensing of nuclear plants could continue without posing a

\footnotetext{
${ }^{12}$ NRC (2011a).

${ }^{13}$ NRC (2011b).
} 
significant risk to public health and safety. However, the Task Force report identified a number of general areas for improvement, rationalization and modernization of NRC regulatory procedures that have evolved over many years, and it made recommendations to codify and harmonize a large set of general and specific safety criteria and procedures so that the regulatory process can operate more efficiently. It recommended specific actions to improve safety that could affect existing and new units. The Task Force report endorsed the NRC's defense in depth strategy and the continued reliance on properly defined design basis accidents with an additional level of safety for individual plant sites.

Among specific recommendations that could affect some existing plants if they are adopted by the NRC include: reevaluating the design basis accident used to account for new data on earthquakes and floods; strengthen station blackout mitigation (loss of station power) for all existing and new units; hardening of vent designs on BWRs with Mark I and Mark 2 containments; improvements in hydrogen control and mitigation inside containments and other buildings; enhancing spent fuel water makeup capabilities; and strengthen emergency preparedness programs. Indeed, the NRC recently announced that nuclear operators employ a new seismic model commissioned prior to Fukushima to reassess the likelihood of earthquakes in their region. This may lead to costly retrofit requirements for some plants which in turn could make it uneconomic to keep them in operation if natural gas and wholesale power prices stay so low. As more information is gained from Fukushima, we can expect the list of recommendations and their priorities to change. It must be noted that the costs of implementing these changes as they affect existing and new plants are not included in the Task Force report, a subject to which we will return presently. 
In the EU, the member countries agreed that all nuclear plants are to be subject to inspections, a set of stress tests, and the specification of a set of "lessons learned" from Fukushima. ${ }^{14}$ The final reports from licensees on these stress tests are due at the end of October and final national reports at the end of the year. These stress tests have not led to any plants being closed for safety reasons so far. Of course, Germany and Switzerland took actions soon after the Fukushima accident which will affect existing plants. On March 15, 2011, the German government permanently shut down the 8 oldest of its 17 nuclear units. In June 2011, the German Parliament passed a law to phase out the remaining plants by 2022 and presumably to build no additional plants. Siemens, the construction and engineering conglomerate that built all 17 of Germany's nuclear plants, announced in September 2011 that it would stop building nuclear power plants anywhere in the world, dropping plans to work with Rosatom to build new plants. ${ }^{15}$

In Switzerland, the Swiss Federal Council has recommended that Switzerland's existing reactors be allowed to continue to operate during their license periods, but that they close at the end of their current licenses and not be replaced. The final reactor would then close in 2034. The proposal was approved by parliament. This recommendation came despite a conclusion by the nuclear regulator that it had identified no new safety issues in light of Fukushima and an earlier referendum supporting the construction of replacement reactors.

In the UK there is uncertainty about the technical and economic opportunities for extending the lives of the Magnox and AGR plants, though some will certainly close as

\footnotetext{
${ }^{14}$ DG Energy (2011).

${ }^{15}$ http://www.nytimes.com/2011/09/19/business/global/19iht-siemens19.html.
} 
their licenses expire for economic reasons. The accident at Fukushima does not appear to have had any effect on this decision. ${ }^{16}$

France recently completed a post-Fukushima safety audit, and recommends substantial investment to improve safety at existing sites. While France continues to be committed to nuclear power and relicensing existing plants, these additional costs may impact the life of specific plants. ${ }^{17}$ Moreover, some of France's plants are located near the German or Swiss borders and it may come under some pressure to close a couple of the older plants. France has lifted safety spending and has stressed the need to have uniform (high) safety standards around the world. Finally, the Socialist Party, historically a strong supporter of nuclear power, has joined forced with the Green parties to strengthen their political power in the coming election for President, and have agreed to close 24 existing nuclear units by 2025 . Whether they will win the election and whether this is a credible commitment, especially with the large unionized work force at these units is uncertain.

The situation is unclear in Belgium (7 reactors). In 2003 the government decided that no new reactors would be built and that the existing reactors would close between 2015 and 2025. In 2009 the government decided to extend the lives of the three oldest plants, but this was not formalized. Belgium was without a government in 2010 and most of 2011 and the caretaker government during that period had decided not to make any decisions until after the EU stress tests are completed.

Of course Japan, the third largest supplier of nuclear energy in the world, is the big wild card. Fukushima Daiichi units 1-4 have been permanently closed, and the future

\footnotetext{
${ }^{16}$ ONR (2011).

${ }^{17}$ ASN (2011).
} 
status of units 5 and 6 is uncertain. More importantly, a large fraction of Japan's remaining 50 operational reactors are not operating at the moment either as a result of the earthquake and/or Tsunami, refueling outages at that time, or subsequent events. Only about 10 of Japan's 50 operational units are now actually operating and there has been significant local opposition to returning them to service. The previous government announced that Japan would move away from nuclear power in favor of renewable energy while the new government has indicated just the opposite. Japanese utilities and regulatory authorities are reviewing potential seismic and flooding design bases, emergency power, spent fuel pools, hydrogen release and venting. This information will determine the needs and costs of remediation and potentially the need to close some plants for safety reasons. Public opposition, especially local public opposition, to restarting a number of the closed plants suggests that public support for Japan's current nuclear power program is under considerable stress. It is clear that the nuclear regulatory regime will be changed significantly. The government recently proposed limiting the operating life of existing reactors to 40 years and requiring substantial retrofits as well as planning for worst-case scenarios.

South Korea recently reaffirmed its plans to extend the life of existing units. China completed a review of operating units and announced some additional safety measures and a plan for a longer term safety assessment.

Any new requirements ultimately issued by regulators to enhance plant safety features and further reduce the probability of a catastrophic accident, will cost money. Especially for merchant nuclear plants in the U.S. and elsewhere, the owners' decisions to continue operating or to relicense existing plants turns on a comparison of the 
incremental costs of adding another twenty years of safe and reliable operating life to the plants and the incremental revenues from the sales of power from the plants. If the cost is too high, it could lead some owners not to seek to relicense their plants and to close existing plants. So, whether or not the response to Fukushima has an effect on future supplies of electricity from existing nuclear plants will depend in part on how costly it turns out to be to meet any retrofit criteria that are ultimately required by regulators.

And the cost side of the equation is more relevant today than it was a few years ago when license renewals began because (a) for those nuclear plants in countries that have adopted competitive wholesale markets, the owners will not be able to turn to regulators to pass these costs through to consumers and (b) the revenue side of the equation has deteriorated. The revenue side of the equation has deteriorated for two primary reasons. First, forecasts of natural gas prices and associated wholesale power prices have come down significantly as low-cost supplies of natural gas from shale are being developed or are likely to be developed in the U.S., Canada, China, and Europe. Second, many countries have adopted renewable energy mandates as components of their programs to reduce GHG emissions. This additional electricity capacity depresses wholesale market prices further and adversely affects the economic attractiveness of base load capacity with slow ramp rates. The more costly are the retrofitting requirements, the more likely it is that some existing plants will decide to retire earlier than is built into pre-Fukushima base-line forecasts.

Most countries with major nuclear programs moved quickly to perform short-term safety assessments of existing plants and to launch longer term assessments of regulatory procedures and safety criteria. And most countries are taking a more measured approach 
than Germany or Switzerland to making policy on existing a new nuclear units by first inspecting existing units to identify clear short-term safety issues at each site, conducting longer term assessments of potential changes in safety requirements at existing sites and potential sites for new plants and their implications (e.g. the U.S., EU, Japan and China). These rapid responses of governments to the accident at Fukushima, assurances that operating plants are safe, and ongoing assessments of issues associated with seismic events, flooding, loss of off-site power, cooling spent fuel pools, venting of hydrogen released during a loss-of-coolant accident, emergency procedures, and other safety issues have helped to mute significant changes in public attitudes towards nuclear power in most countries. For example, a Gallup poll assessing attitudes in the US in May 2011, after the Fukushima accident, with attitudes in May 2001, found that responses regarding the safety of nuclear power and the necessity of increasing the number of nuclear power plants had not materially changed. ${ }^{18}$

Decisions already made by Germany and Switzerland and the prospect that Japan and selected units in other countries end up retiring earlier than anticipated can have a significant effect relative to pre-Fukushima base-line nuclear generation forecasts. Germany, Switzerland and Japan together account for nearly 20\% of global nuclear power production. If these countries all retire their nuclear plants early or decide against license extension, the global nuclear generation baseline will shrink. Selected closures in other countries as a result of higher compliance costs or local political considerations will shrink the baseline further. However, we consider that it is likely that most reactors will continue to operate and be relicensed and the direct effects of Fukushima on the operation of existing plants will be at most $20 \%$ of current nuclear generation.

\footnotetext{
${ }^{18}$ http://www.gallup.com/poll/146939/majority-americans-say-nuclear-power-plants-safe.aspx.
} 


\section{New Plant Construction}

The EIA forecasts use the year 2035 as their terminal year. This is unfortunate and potentially misleading. Many existing nuclear plants (essentially all existing U.S. plants) will retire between 2035 and 2050, even if they are able to secure 20-year license extensions. This means that sustaining nuclear's share of total electricity generation, would require substantial construction of new nuclear plants well before mid-century both to meet growing electricity demand and to replace retiring units.

Turning first to the OECD countries with existing nuclear power programs, several countries where there was the possibility that they would build nuclear power plants to replace those that are retiring have now reversed course. These include Germany, Switzerland, Italy, Spain, and Belgium (probably). The situation in Japan necessarily remains in flux, but as the country with the third largest nuclear program a decision to move away from nuclear power, together with Germany's decision would have a material effect on future trends. However, in the rest of the OECD countries with existing nuclear power programs—excepting South Korea, we believe that construction of new nuclear capacity would have been slow absent Fukushima. Any tightening of safety requirements resulting from the Fukushima accident will only make the economic status of nuclear power less attractive.

A potential exception is the UK, where a large fraction of the existing fleet of Magnox and AGR nuclear plants is likely to retire for economic and technical reasons. Thus, there is a replacement market in the UK that does not yet exist in the U.S., France, etc. In 2008, the UK government decided to support building new nuclear plants, and that decision has, so far, not changed as a result of Fukushima, though the UK is participating 
in the larger EU review and this will delay pursuing new construction pending the outcome of "lessons learned" from Fukushima. ${ }^{19}$ Three consortia have been pursuing construction of several new nuclear units (EDF-Centrica, RWE-E.On, GDF-Iberdrola) using modern light water reactor technologies.

However, the prospective new builds in the UK face significant economic challenges. The UK has a very large and heavily subsidized renewable energy program, and while natural gas prices are still high compared to the U.S., additional supplies of LNG, and pipeline supplies from Norway, Russia and Central Asia are coming on line, and shale gas deposits have been identified in England and other parts of Europe. In addition, England and Wales has the most liberalized wholesale spot electricity market in the world, with no capacity payments or long term contracts. This market does not appear to be conducive to investments in nuclear generation. In order to attract nuclear power investment the government is pursuing floor prices for carbon allowances and additional electricity market reforms are planned, including long term contracts and a capacity payment mechanism. ${ }^{20}$ Nevertheless, in September 2011, Scottish and Southern reported that it was withdrawing from the GDF/Iberdrola consortium and would pursue renewable energy opportunities instead, though the other members of the consortium indicated that they would continue. ${ }^{21}$ It has also been reported that RWE is re-evaluating investing in new nuclear plants in the UK. ${ }^{22}$ At least in the case of RWE this decision is

\footnotetext{
19 Rob Edwards (5 April 2011) "UK nuclear plans on hold after Fukushima". The Guardian (London). http://www.guardian.co.uk/environment/2011/apr/05/uk-nuclear-plan-fukushima; Kari Lundgren (July 28, 2011). "Centrica Says Nuclear Plants Likely Delayed, Slows Spending". Bloomberg Businessweek.http://www.businessweek.com/news/2011-07-28/centrica-says-nuclearplants-likely-delayed-slows-spending.html.

${ }^{20}$ http://www.decc.gov.uk/en/content/cms/legislation/white_papers/emr_wp_2011/emr_wp_2011.aspx.

${ }^{21}$ http://www.guardian.co.uk/business/feedarticle/9861579.

22 http://www.guardian.co.uk/environment/2011/oct/07/rwe-uk-nuclear-power.
} 
indirectly related to Fukushima, as the German government's decision to close its older nuclear plants immediately has had significant adverse effects on the finances of German utilities. It does appear that the UK government is going to great lengths to support nuclear power as part of its GHG mitigation strategy.

Of course, the economic situation confronting investment in nuclear power could change. Experience with the few new plants that are still expected to be built in the U.S. and Europe may demonstrate that current construction cost estimates are too high (so far France and Finland's experience has been just the opposite) and that optimistic break-in periods allowing these plants to achieve high capacity factors quickly are realistic despite the more pessimistic history—see Du and Parsons (2010). Natural gas prices could increase again. Countries could back off of lavish subsidies and goals for renewable energy and energy efficiency programs. This experience will probably take a decade to accumulate. Thus, with the exception of South Korea, we do not expect a dramatic increase in investment in new nuclear plants in the OECD countries with existing programs in this decade, even absent Fukushima.

In the non-OECD countries the major action is in China, first and foremost, as well as in Russia and the former FSU countries in Eastern Europe, and the rest of Asia. The post-Fukushima assessments have had little direct effect so far on plans to construct new nuclear units in the countries where significant nuclear programs were being planned prior to Fukushima. China did reduce its plan for new plants by 2020 by 10 GWe, but many considered the original 100 GWe goal for 2020 unrealistic and the reduction may have reflected considerations other than safety. Russia, India, and most other non-OECD countries are continuing as planned, pending additional information from reactor safety 
audits and more information from Fukushima. After reviewing the post-Fukushima situation some countries have now decided that they will not enter or re-enter the nuclear expansion business (e.g. Taiwan, Chile, Israel, Venezuela), but the impact on the aggregate global nuclear supply would have been small anyway. On the other hand, nonnuclear Turkey, Saudi Arabia, Vietnam, and Abu Dhabi have recommitted to start building nuclear power plants.

We do believe that the countries that are entering the nuclear power business and those that are considering dramatic increases in nuclear capacity may be underestimating the challenges associated with these plans. China currently has 17 operating reactors with a capacity of 11 GWe. It has 26 units under construction and plans to increase it nuclear capacity by a factor of seven or eight by 2020. It is relying on two foreign companies (Westinghouse/Toshiba and Areva) and two Chinese companies (China National Nuclear Corp. and State Nuclear Power Technology Corp.) to lead this expansion. If there is one thing that we learned from the large expansion of nuclear capacity in the U.S. in the 1970s and 1980s it is that many unexpected construction and operating problems can emerge if the program is rushed, operates subject to constraints on the supply of skilled workers (like high-skilled welders, engineers, and construction managers) and does not build in time to respond to unexpected problems and to learn from experience. Successful nuclear power programs must meet economic, stringent safety and reliability criteria. We think that there is a serious risk that China's program is too ambitious to achieve these criteria. Given the expected rapid growth in electricity demand, the small share of production contributed by nuclear power today (2\%) and under the plan (6\%), its dependence on imports of fossil fuels, and its goal of reducing 
dependence on dirty domestic coal supplies, China may be willing to sacrifice on the economics in order to meet energy security and environmental goals. However, China cannot fail to meet high safety standards and this may prove to be a constraint on how quickly its nuclear program can actually proceed.

Countries like Vietnam, Saudi Arabia, Turkey, and Abu Dhabi face additional challenges. They do not have the regulatory infrastructure, internal technical expertise, waste handling, non-proliferation, or industrial structures necessary to rapidly launch a nuclear power program. Indeed, one of the reasons they are interested in starting such a program is to gain and internalize technical expertise and some industrial infrastructure to help to advance their economies. Abu Dhabi has taken an approach that "outsources" most of what is needed to start a nuclear power program in all of these dimensions. It would be wise for other countries in this group to learn from its experience before moving too quickly.

\section{Conclusions}

We believe that the primary determinants of the future path of operation of existing nuclear plants and investments in new nuclear power globally continue to be economic considerations, perceived energy security considerations, environmental considerations, and public acceptance. We are surprised that public acceptance has not been shaken more by the accident at Fukushima and, if further lessons learned from Fukushima do not increase the political backlash, the same factors that influenced the future trajectory of nuclear generation pre-Fukushima are likely to continue to dominate. We think that it is likely that tighter safety requirements will increase the costs of both 
existing and new plants, but aside from the countries mentioned which have or are considering dropping nuclear power as an option, no government has yet issued final new safety regulations or indicated that they will lead to dramatic changes in current safety criteria or large increases in costs to meet them. We will learn more over the next couple of years as current assessments are completed. So, it seems clear that the accident at Fukushima will contribute to a reduction in future trends in the expansion of nuclear energy, but at this time these effects appear to be quite modest at the global level. The future paths for countries like Germany, Switzerland, and Japan will be affected significantly, but so far most other countries have not made significant changes in their support for nuclear power or adopted costly changes in safety criteria. In coming to this conclusion we recognize that there are still many lessons to be learned from the accident at Fukushima.

We close with one observation. After the accident at Three-Mile Island, and following the recommendations of the Kemeny Commission, the U.S. nuclear industry created an independent organization called the Institute of Nuclear Power Operations (INPO) to facilitate the sharing of best practices within the industry and to use peer reviews of nuclear operating procedures at each nuclear plant to inform senior management and boards of directors about the safety performance of the nuclear plants that they own and operate. INPO's reviews of plant operations are taken extremely seriously by U.S. nuclear operators and the INPO ratings of nuclear plants have become the gold standard used to evaluate performance and to initiate changes when peer reviews yield low INPO ratings. While the workings of INPO are consciously invisible to the public they are taken seriously by the industry and have helped to improve safety 
performance indicia for U.S. plants over time, applying a common set of safety criteria and the tough love of peers. All nuclear operators are willing to participate in this information sharing, inspection, and peer review process because they know that if one nuclear unit has a serious safety problem it can affect them all. INPO has played a major behind the scenes role providing the best information available about lessons learned from Fukushima and working with the nuclear industry to identify responses necessary to maintain safe operations for U.S. plants.

The World Association of Nuclear Operators (WANO) was created in 1989 and is frequently advertised as being the international equivalent of INPO. However, WANO appears to be a pale shadow of INPO. WANO has not established rigorous global operating safety standards or a standardized and frequent peer review inspection and reporting program. Individual countries interact with WANO (or not) in different ways. We wonder when the Fukushima site was last inspected by a WANO team and what its ratings were.

If Fukushima teaches us anything it is another reminder that all operators of nuclear power plants and their regulators must take nuclear plant safety extremely seriously, harmonize safety criteria for nuclear power plants around the world using best practices and institute the kind of rigorous inspection, peer review and rating program that INPO has created. Senior management of companies need to be involved and hear from the inspections teams the good and the bad about the operation of their plants and be required to develop and implement remediation plans where necessary. While the international nuclear industry appears so far to have dodged being hit square in the head 
by a bullet from Fukushima, it should not expect that it will get another chance if there is another serious nuclear accident anywhere in the world. 


\section{References}

ASN, 2011, Complementary Safety Assessments of the French Nuclear Power Plants (European "Stress Tests”), French Nuclear Safety Authority (ASN), December.

DG Energy, 2011, After Fukushima: EU Stress tests start on 1 June, EU Commissioner for Energy, Press Release IP/11/640, Brussels, 25 May.

Du, Yangbo, and John E. Parsons, 2009, Update on the Cost of Nuclear Power, Center for Energy and Environmental Policy Research Working Paper \#09-004.

Du, Yangbo, and John E. Parsons, 2010, Capacity Factor Risk at Nuclear Power Plants, Center for Energy and Environmental Policy Research Working Paper \#2010-016, November.

EIA, 2010a, Annual Energy Outlook 2010, With Projections to 2035, US Department of Energy, Energy Information Administration, DOE/EIA-0383(2010), April.

EIA, 2010b, Updated Capital Cost Estimates for Electricity Generation Plants, US Department of Energy, Energy Information Administration, November.

EIA, 2011a, Annual Energy Outlook 2011, With Projections to 2035, US Department of Energy, Energy Information Administration, DOE/EIA-0383(2011), April.

EIA, 2011b, International Energy Outlook 2011, US Department of Energy, Energy Information Administration, DOE/EIA-0484(2011), September.

Institute for Nuclear Power Operations (INPO), 2011, Special Report on the Nuclear Accident at the Fukushima Daiici Nuclear Power Station, INPO 11-005, November 2011.

Joskow, Paul L., 2011a, Comparing the Costs of Intermittent and Dispatchable Electricity Generating Technologies, American Economic review: Papers and Proceedings 100(3), 238-241.

Joskow, Paul L., 2011b, Comparing the Costs of Intermittent and Dispatchable Electricity Generating Technologies. MIT CEEPR Working Paper WP-2010-013 as revised February 9, 2011. http://econ-www.mit.edu/files/6317.

NRC, 2011a, NRC Issues Mid-Cycle Assessments for Nation's Nuclear Plants, U.S. Nuclear Regulatory Commission, Press Release No. 11-16, September 6.

NRC, 2011b, Recommendations for Enhancing Reactor Safety in the $21^{\text {st }}$ Century, The Near-Term Task Force Review of Insights from the Fukushima Dai-Ichi Accident, U.S. Nuclear Regulatory Commission, July 12. 
Nuttal, W.J., 2005, Nuclear Renaissance-Technologies and Policies for the Future of Nuclear Power, Institute of Physics Publishing, Bristol and Philadelphia.

ONR, 2011, Japanese earthquake and tsunami: Implications for the UK nuclear industry, Final Report, UK Office for Nuclear Regulation, HM Chief Inspector of Nuclear Installations, ONR Report ONR-FR-REP-11-002 Revision 2, September. 